\title{
CATEGORIA D) ASPECTO NO SINTAGMA VERBAL RUSSO.
}

\section{Victória Namestnikov El Murr}

Não raro encontramos a afirmação de que a parte mais complexa das categorias gramaticais russas cabe ao sintagma verbal; julgamos extremamente oportuno afirmar que, dentro deste contexto, o primeiro lugar pertence ao aspecto.

Nossa atenção foi chamada para o fato devido aos freqüentes erros que os alunos cometem por ocasião da aplicação prática dos conhecimenots teóricos; o mesmo ocorre, impreterivelmente, com indivíduos que dominam a língua de modo a fazer dela uso quase fluente, mas o emprego do aspecto verbal constitui-se numa pausa obrigatória.

Este fatos evidenciam uma diferente visão do mundo entre os falantes da língua russa e os do português no Brasil, para não generalizarmos. Despertado o interesse, quisemos procurar os semas correspondentes em uma e outra língua. Quanto mais nos aprofundamos no estudo, maior a complexidade para estabelecer um paralelismo válido; comprova-o vastissima bibliografia concernente à questão.

A primeira dificuldade que se nos apresentará é a própria conceituação de aspecto. Vejamos algumas:

- Aspectos: refe:em-se ao grau de desenvolvimento da idéia expressa pelo verbo (= duração) (1);

- A perfectividade é um sema contido em certos morfemas lexicais e que se encontram em oposição binária com a imperfectividade (2);

(1). - SPINA, Segismundo - Dicionário Prático de Verbos Conjugados, 2å ed., São Paulo, Ed. F.T.D., S/A, s.d., p. 11.

(2) - PAIS, Cidmar Teodoro e outros - Estruturas Lingüísticas do Português, São Paulo Difusão Européia do Livro, p. 48. 
- Aspecto é a propriedade que tem uma forma verbal de designar a duração do processo (momentâneo ou durativo) ou aspecto piopriamente dito sob que ele é considerado pelo falante (3);

- Aspecto é a visão objetiva da relação entre a ação expressa pe'o verbo e a idéia de duração ou desenvolvimento. É pois, a representação espacial do processo (4);

- Todo verbo eslavo é perfectivo ou imperfectivo. Estas oposiçōes de "perfectivo" e de "imperfectivo" são as que cenominamos oposiçōes de "aspecto" (em russo vid)

As gramáticas russas, destinadas a indivíduos falantes de outros idiomas, são, de modo geral, muito cautelosas ao tratar do aspecto verbal, fato que pode ser visto nos títulos como estes:

"Noções sobre os aspectos do verbo";

"Conceito dos aspectos verbais"; etc.

,Tomamos a liberdade de transcrever a seguinte citação, encontrada na Tese de Doutoramento do Prof. Ataliba de Castilho, (6) por acharmos que exprime de modo extremamente preciso a problemática que ora nos ocupa:

"Il n'y a guère en linguistique de question plus difficile que celle de l'aspect, pa:ce qu'il n'y en a pas de plus controversée et sur laquelle les opinions divergent Davantage. On n'est d'accord ni sur la définition même de l'aspect, ni les rapports de l'aspect et du temps, ni sur la façon dont l'aspect s'exprime, ni sur la place qu'il convient de reconnaître à l'aspect dans le système verbal des différentes langues" (7)

Fascinados pela complexidade do tema procuramos,, retrocedendo no tempo, as raízes históricas da conceituação aspectual. No início do século XIX os gramáticos russos confundiam o estudo do aspecto com o dos tempos e discutiam sobre a extensão do seu alcance semântico. De modo geral, a primeira metade do século passado correspondeu ao período inicial do estudo das categorias aspectuais e temporais

(3) - CÂMARA Jr., J. Mattoso - Dicionário de Filologia e Gramática Referente à Língua Portuguesa, 6a ed., Rio de Janeiro Joozn Editor, 1974.

(4). - CASTILHO, Ataliba T de - Introdução ao Estudo do Aspecto Verbal na Língua Portuguêsa, Marília, 1966.

(5) . - MEILlET, A. - Le Slave Commun, 2a ed. revista Paris, Libr. Honoré Champion, 1934, p. 284.

(6) - CASTILHO, Ataliba T. de - op. cit., p. 34.

(7) - VENDRYES - in A. Klum - Verbe et Adverbe, p. 23. 
do sintagma verbal russo. Delinearam-se as relações básicas aspectotempo e suas características gerais, mas, a realidade intrínseca da categoria aspectual, a relação entre os significantes quantitativos e qualitativos permaneciam inexplicadas.

Cabe a G. Pávski iniciar uma nova fase na história do estudo dos aspectos, tomando consciência da particularidade desta categoria, transforma-a em centro gramatical do sistema verbal russo. Por analogia com os adjetivos, denomina os aspectos de graus e descreve com muita precisão a técnica da formação aspectual. Simplifica assim a teoria ocidental dos tempos, introduzida por Lomonossov, e coloca-os numa dependência total das variantes aspectuais. Entende por grau a medida de duração e a amplitude de ação. Evidentemente, seus trabalhos suscitam várias críticas, sobretudo no sentido de que não seria possível misturar com o grau de amplitude espacial a força de ação; e o grau de duração com o grau de proximidade ou distância de ação.

Potebniá é o verdadeiro continuador da obra de Pávski; nos estudos que desenvolve, prova que a divisão em graus, feita por este, é incompleta e que nos limites de um mesmo grau encontram-se vários tipos de verbos. Pávski deixara de lado o problema básico do determinado - indeterminado, que não exclui a realidade da duração. Qualquer verbo de cada um dos graus de Pávski poderia ser indeterminado mas, segundo Potebniá, ele poderia ser também perfectivo.

Os estudos de Pávski serviram de ponto de partida para uma nova teoria dos aspectos de K.S. Aksakov, que deu ao conceito de grau características mais qualitativas onde se determinava a própria ação na sua ocorrência efetiva, nos seus momentos de incidência. Considera a base da conjugação como sendo a categoria dos aspectos, e o centro da conjugação como representado pelas mudanças aspectuais. Reconhece a existência de variantes de um mesmo radical como formas de um mesmo verbo que seriam as qualidades de ação, e de onde emanaria o conceito de tempo.

Esta teoria foi, por sua vez, aprofundada por N.P Nekrassov, que tentou substituir a dualidade quantitativo-qualitativa pela determinação da categoria do aspecto.

Entretanto, do que pudemos concluir das leituras feitas, (8) o papel preponderante no estudo da categoria aspectual coube, sem dúvida, a Potebniá. Embora não tendo estabelecido uma teoria definitiva e mudando seus pontos de vista no decorrer da pesquisa, ele conse-

(8). - VINOGRADOV, V V. - Rússki lazík (A Língua Russa), 2a ed., Ed. Escola Superior, Moscou, 1972. p. $337-511$. 
guiu, a partir da crítica exaustiva das teorias anteriormente citadas, chegar a resultados realmente significativos. Dando grande importância à diferenciação do grau de duração, começou a relacionar a idéia de aspecto com as categorias de perfectividade e imperfectividade. Dizia que sob a denominação de aspecto (vid) subentendiam-se, até então, duas categorias totalmente diversas: de um lado a perfectividade e a imperfectividade e de outro os graus de duração. Desta forma a palavra vid encobria um caráter duplo que seria conveniente eliminar.

As categorias do perfectivo e do imperfectivo subordinaram a si as variações de grau de duração. Entretanto, segundo Potebniá, o sistema dos aspectos não deve constituir-se na descr.ção a sim na história da sua formação. Acredita que a confusão na conceituação é devida à falta de pontos de vista históricos através dos quais seria possível veficar a ordem gradativa da estratificação dos significados, dos chamados aspectos.

Aliás, este mesmo ponto de vista foi-nos oralmente expresso pelo Prof. Gre:mas por ocasião de sua permanência na USP em outubro :le 1975.

Diferentes aspectos passam a integrar o código lingüístico em diferentes épocas, portanto um aspecto cuja introdução foi posterior não poderia servir de modelo para um anterior $\mathrm{A}$ formação dos vários graus de duração é anterior à sua constituição em categorias gramaticais. Perfectivo-imperfectivo, de um lado, e os graus de duração, de outro, não constituem um continuum, mas, segundo Potebniá, referemse um ao outro como duas ordens distintas nos diferentes níveis da língua. Acredita que a duração expressa pelos sintagmas verbais não é med:da de modo objetivo mas sim sujeita-se como que a uma med.da imposta pela própria língua, tendo por unidade o "grau dos verbos" Frisa que a momentaneidade ou a incoatividade não pode ser confundida com a perfectividade. Relaciona a noção do aspecto com a obrigatoriedade da dependência frástica, contextual. Reconhece a influência da preposição sobre o aspecto, que pode ser provada pelas mudanças internas da função verbal. Com base na diferenciação da idéia de perfectividade e imperfectividade nos versos compostos, inicia o estudo das mesmas diferenciações nos verbos não preposicioandos, mas que exprimem diferentes graus de duração.

V V Vinogradov, um dos mais eminentes lingüistas soviéticos, reconhecendo que a teoria do aspecto no sintagma verbal russo é uma das partes mais complexas, mais discutíveis e menos alucidadas da gramática russa, afirma que, até o momento em que escreve, não foi possível aos gramáticos russos encontrar a diferenciação básica que sec- 
ciona o verbo russo em duas partes distintas: perfectivo e imperfectivo. (9)

$\mathrm{Na}$ realidade encontramos três colocações básicas para o problema, sobretudo nas gramáticas destinadas ao manuseio dos escolares, seja para o ensino de estrangeiros, seja para o de estudantes russos.

$\mathrm{I}$ - $\mathrm{O}$ aspecto imperfectivo indica duração ou durabilidade do desenvolvimento da ação; o aspecto perfectivo indica uma ação terminada. Entretanto, nota Vinogradov, com justa razão, que tal definição entra em choque com os diversos matizes implícitos nos complexos verbos de aspecto perfectivo, compostos por prefixação. Tal fato exigiu que se introduzissem nesta colocação as noções de início, término ou desenvolvimento de ação mas, de qualquer forma, isto não chegou a esgotar as possibilidades reais apresentadas concretamente no uso do código linguístico.

II - Os aspectos exprimem-se como indicadores de várias etapas, de diferentes momentos de ação: o perfectivo indica o início e o fim da ação, o imperfectivo designa o seu desenvolvimento, o desenrolar compreendido entre o momento inicial e o final. Novamente os matizes oferecidos pelos provérbios não chegam a ser abordados na sua totalidade. A problemática gramatical consiste justamente na delimitação, na separação dos significados aspectuais formais dos significados reais e da sua sutil diversificação introduzida na categoria aspectual por intermédio dos provérbios.

III - A teoria que diversifica os aspectos tomando por base as analogias espaciais. O aspecto perpectivo exprime a execução do ato, e o momento temporal indica uma ação sem continuidade, punctiva, em que o início coincide com o término (inceptivo ou incoativo). $O$ aspecto imperfectivo exprime uma ação que dura, uma ação "linear" (cursivo). Os aspectos empregam-se dependendo do desejo do emissor no sentido de exprimir apenas o momento inicial ou final da ação, ou, pelo contrário, a continuidade integral do tempo no decorrer do qual se desenrola a ação (10). Entretanto, não podemos deixar de reconhecer a impossibilidade de enquadrar, mesmo nesta conceituação mais complexa que as anteriores, uma série de verbos perfectivos através dos quais a ação se desenrola como um processo associativo, que atinge o seu fim por meio de um desenvolvimento gradativo ou por meio de uma realização de atos independentes e isolados que se sucedem, constituindo um todo.

(9) - VINOGRADOV, V V. - op. cit., p. 391-394.

(10) - SAUSSURE, Ferdinand de - Cours de Linguistique Générale, Paris, Payot, 1969, p. 163-166. 
$\mathrm{Na}$ teoria de F.F Fortunov, o aspecto perfectivo nas línguas eslavas exprime-se em função de um tempo determinado (durativo ou não) do ponto de vista espacial, enquanto que no aspecto imperfectivo o mesmo fato observa-se sem relação com um tempo qualquer Os aspectos são correspondentes e seria mais preciso "determinado" e "indeterminado" (11).

Convém levar em conta, ainda, os estudos que reduzem o aspecto perfectivo à expressão de um resultado:

"A expressão do resultado constitui-se numa das características básicas do aspecto perfectivo, não sendo, poém, a única. Até os lingüistas que frisam a necessidade da existência de um resultado no aspecto perfectivo, não negam que a função básica deste aspecto é a delimitação ou o afastamento da idéia de duração da ação e concentração da atenção num dos momentos do processo, como sua finalidade. A designação da ação no seu desenvolvimento, não sendo limitada pela idéia de restrição no processo total, é o significado básico, geral, do aspecto imperfectivo. Apresenta-se como significado "comum" e real do significado do verbo, como sua norma gramatical. (.. o o aspecto impe:fectivo, designando "ação-estado não qualificados" (Chakhmatov), co responde à origem, a uma base neutra do relacionamento aspectual. A correspondência entre o aspecto perfectivo e imperfectivo exprime-se pelo fato de que o verbo russo geralmente se apresenta num sistema de fo mas interdependentes, que se referem a duas séries "aspectuais" pa:alelas" (12)

Diante do exposto, torna-se evidente a dificuldade de emprego correto do aspecto verbal russo para falantes de outros códigos. Por falta de elementos científicos precisos que o regulamentem, somos quase levados a admitir que se trata de uso subjetivo se não tivermos presente a afirmação de uma logicidade histórica.

Para concluir, não podemos deixar de lembrar que a dificuldade na aplicação prática dos coinceitos teóricos por parte dos nossos alunos, em particular, consiste sobretudo no fato de que o russo conservou no seu sistema verbal a predominância do aspecto sobre o tempo, fato inverso do que ocorre no português.

(11) - In Vinogradov, V.V. - op. cit., pp. 393-394.

(12). - Idem, pp. 394. 